\title{
Blood Phosphorus Concentration as an Indicator of Phosphorus Deficiency in Growing Cattle ${ }^{\dagger}$
}

\author{
Rob Dixon ${ }^{1, *}$, Stephen Anderson ${ }^{2}$, Lisa Kidd ${ }^{3}$ and Mary Fletcher ${ }^{1}$ \\ 1 Queensland Alliance for Agricultural and Food Innovation (QAAFI), The University of Queensland, \\ 25 Yeppoon Road, Rockhampton, QLD 4701, Australia; mary.fletcher@uq.edu.au \\ 2 School of Biomedical Sciences, The University of Queensland, St Lucia, Brisbane, QLD 4072 Australia; \\ stephen.anderson@uq.edu.au \\ 3 School of Veterinary Sciences, The University of Queensland, Gatton, QLD 4343 Australia; \\ 1.kidd@uq.edu.au \\ * Correspondence: r.dixon2@uq.edu.au \\ † Presented at the Third International Tropical Agriculture Conference (TROPAG 2019), Brisbane, Australia, \\ 11-13 November 2019.
}

Published: 1 April 2020

\begin{abstract}
Inadequate intakes of phosphorus $(\mathrm{P})$ by cattle can cause $\mathrm{P}$ deficiency and severely reduce productivity. Blood inorganic $\mathrm{P}$ concentration $(\mathrm{Pi})$ is often used as an indicator of $\mathrm{P}$ deficiency. Results from two experiments (E1 and E2) with young cattle grazing tropical P-deficient rainy season pastures without or with additional $\mathrm{P}$, or fed in pens on higher energy pelleted diets ranging in P concentration (E3), were used to examine the relationships between Pi and liveweight (LW) gain. When Pi was $>2.0 \mathrm{mmol} / \mathrm{L}$ average $\mathrm{LW}$ gains were $0.71,0.85$ and $1.04 \mathrm{~kg} /$ day in E1, E2 and E3, respectively. These differences between experiments were most likely associated with diet limitations other than P. LW gain was related curvilinearly in E1 and E2, and linearly in E3, with Pi. The Pi ranged from ca. $1.0 \mathrm{mmol} / \mathrm{L}$ through to $2.5-3.0 \mathrm{mmol} / \mathrm{L}$ in each experiment. The reductions in $\mathrm{LW}$ gains from the maximum at $\mathrm{Pi}>2.0 \mathrm{mmol} / \mathrm{L}$ for several lower $\mathrm{Pi}$ concentrations were calculated from these relationships. At $\mathrm{Pi}=1.0 \mathrm{mmol} / \mathrm{L}$ the $\mathrm{LW}$ gains were $36-60 \%$ of the maximum, at $\mathrm{Pi}=1.5 \mathrm{mmol} / \mathrm{L} \mathrm{LW}$ gains were $59-84 \%$ of the maximum, and at $\mathrm{Pi}=2.0 \mathrm{mmol} / \mathrm{L}$ the $\mathrm{LW}$ gains were $82-98 \%$ of the maximum. The reductions in LW gain at each Pi were substantially greater for E3 than for E1 and E2. It is concluded that the Pi threshold indicative of P deficiency varies with the diet quality and that the threshold values are substantially higher with higher diet quality.
\end{abstract}

Keywords: phosphorus deficiency; cattle; diagnosis; blood P concentration

Conflicts of Interest: The authors declare no conflict of interest.

(C) 2020 by the authors. Licensee MDPI, Basel, Switzerland. This article is an open access article distributed under the terms and conditions of the Creative Commons Attribution (CC BY) license (http://creativecommons.org/licenses/by/4.0/). 